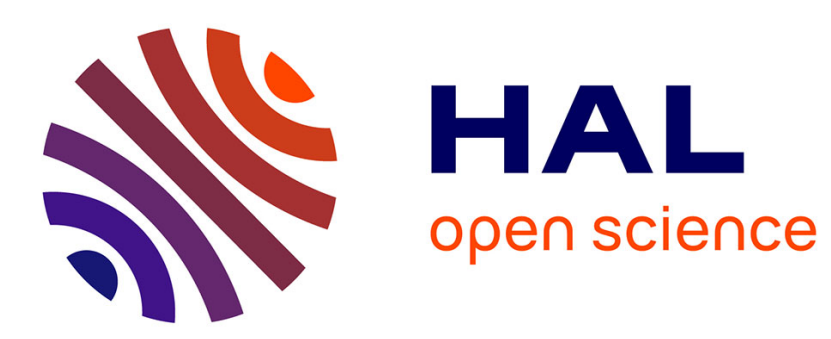

\title{
Positions during the first stage and the passive second stage of labor: A survey of French midwives
}

Chloé Barasinski, Anne Debost-Legrand, Didier Lemery, Françoise Vendittelli

\section{To cite this version:}

Chloé Barasinski, Anne Debost-Legrand, Didier Lemery, Françoise Vendittelli. Positions during the first stage and the passive second stage of labor: A survey of French midwives. Midwifery, 2018, 56, pp.79-85. 10.1016/j.midw.2017.10.010 . hal-01652817

\section{HAL Id: hal-01652817 https://hal.uca.fr/hal-01652817}

Submitted on 30 Nov 2017

HAL is a multi-disciplinary open access archive for the deposit and dissemination of scientific research documents, whether they are published or not. The documents may come from teaching and research institutions in France or abroad, or from public or private research centers.
L'archive ouverte pluridisciplinaire HAL, est destinée au dépôt et à la diffusion de documents scientifiques de niveau recherche, publiés ou non, émanant des établissements d'enseignement et de recherche français ou étrangers, des laboratoires publics ou privés. 
Positions during the first stage and the passive second stage of labor: a survey of French midwives

Chloé Barasinski, RM, MPH ${ }^{\mathrm{a}}$, Anne Debost-Legrand, MD, MPH ${ }^{\mathrm{a}, \mathrm{b}}$, Didier Lemery, MD, PhD, Professor ${ }^{\mathrm{a}, \mathrm{b}, \mathrm{c}}$, Françoise Vendittelli, MD, PhD $^{\mathrm{a}, \mathrm{b}, \mathrm{c}}$

${ }^{\text {a } U n i v e r s i t e ́ ~ C l e r m o n t ~ A u v e r g n e, ~ C N R S, ~ C H U ~ C l e r m o n t-F e r r a n d, ~ S I G M A, ~ I N S T I T U T ~}$ PASCAL, F-63000 Clermont-Ferrand, France ;

${ }^{\mathrm{b}}$ Réseau de Santé en Périnatalité d'Auvergne, F-63000 Clermont-Ferrand, France ;

${ }^{\mathrm{C}}$ AUDIPOG (Association des Utilisateurs de Dossiers Informatisés en Pédiatrie, Obstétrique et Gynécologie), RTH Laennec Medical University, 7 rue Guillaume Paradin, 69372 Lyon Cedex 08, France.

Corresponding author: Chloé Barasinski, Centre Hospitalier Universitaire de ClermontFerrand, Hôpital Estaing, Pôle Femme et Enfant, Recherche Clinique en Périnatalité, 1 place Lucie et Raymond Aubrac, 63003 Clermont-Ferrand Cedex 1, France. Tel: (33) 04737550 89, e-mail: cbarasinski@chu-clermontferrand.fr. 


\begin{abstract}
Objective: The objective of our study was to describe the practices reported by French midwives during labor (first stage and passive phase of the second stage).
\end{abstract}

Design: This cross-sectional internet questionnaire surveyed French midwives who attended at least one delivery in 2013.

Setting: This open survey was posted on a website from June 15 through December 1, 2014.

Participants: 1496 midwives from 377 maternity units participated in the study. Nearly 93\% of the midwives worked in an obstetric unit, $5.9 \%$ had a mixed practice, and $1.3 \%$ worked in private practice.

Measurements and findings: During the first stage of labor, midwives reported suggesting that women without epidural analgesia use a birthing ball $(98.1 \%)$ and that they walk around (97.4\%). For women with epidural analgesia, most suggested motion in horizontal positions. Epidural analgesia was proposed more often by midwives from level II (75.7\%) and level III $(73.5 \%)$ maternity wards than by those at level 1 units $(57.7 \%)(p<0.0001)$. The midwives preferred a lateral position during the first stage for women with epidural analgesia and during the second stage for women both with and without it. Midwives in practice for 5 years or less suggested a kneeling position for women with epidural analgesia more often than more experienced midwives.

Key conclusion: The practices of French midwives vary with their place of practice and their experience.

Implications for practice: To promote normal labor, French midwives must reappropriate vertical positions and analgesic alternatives to epidurals. 
Keywords:

Labor; lateral position; maternal position; medicalization of childbirth; midwifery practice. 


\section{Introduction}

France has the highest birthrate in Europe, with around 800,000 babies born each year (Bellamy and Beaumel, 2016). Most births result from non-operative vaginal deliveries (66.9\%), and of these, $79.7 \%$ are supervised directly by midwives (Blondel and Kermarrec, 2011). Regardless of the mode of delivery, midwives are always present to support the woman during labor, either alone or in association with a doctor, depending on the woman's level of risk (Blondel and Kermarrec, 2011). Periodic national surveys (Blondel and Kermarrec, 2011) and a national database with information submitted by volunteer maternity units (Audipog) provide extensive data about the course of pregnancy and maternal and neonatal outcomes in France. None of this information, however, describes maternal positions during labor or midwives' practices during the different stages of labor.

Beyond the analgesic aspects that some positions during labor may provide, these positions can also affect the course of labor and maternal and neonatal outcomes. Nonetheless, the scientific literature currently struggles to identify the positions that should be recommended to women (Gupta and Nikodem, 2000). Vertical positions may reduce aortocaval compression, increase uterine contractility, and improve the alignment between the uterus and the pelvis, thereby facilitating fetal progression (Gupta et al., 2012). Numerous authors have compared vertical and horizontal positions during labor (Kemp et al., 2013; Lawrence et al., 2013). In their meta-analysis about the first stage of labor for women without epidural analgesia, Lawrence et al. (2013) found that the group of women in vertical positions had a first stage 1 hour and 22 minutes shorter than those in horizontal positions; they also had a lower risk of cesarean delivery (RR 0.71; 95\% CI 0.54, 0.94) and used epidural analgesia less often (RR 0.81; 95\% CI 0.66, 0.99). Among women with epidurals, outcomes do not differ for those in upright or horizontal positions (Kemp et al., 2013). During the second stage of labor, positions used during the passive phase (also referred to as the descent phase in France: from 
full cervical dilation until the beginning of expulsive efforts) should be distinguished from those used at delivery during maternal pushing (Kemp et al., 2013). Kemp et al. found that during this passive second stage, again, maternal and neonatal outcomes for the women with epidural analgesia did not differ according to whether their position was horizontal or vertical (Kemp et al., 2013). This passive second stage has been studied much less among women without epidural analgesia, and positions during this phase have not been studied at all.

Beyond maternal and fetal outcomes, some authors envision maternal positions during labor as "treatment", most especially for fetuses in posterior positions. These fetal positions, which may be more frequent among women with epidural analgesia (Lieberman et al., 2005), can cause several different maternal complications, including both cesarean and operative vaginal deliveries, and third- and fourth-degree lacerations (Fitzpatrick et al., 2001). Nonetheless, recent randomized clinical trials have not succeeded in finding a particular maternal position that facilitates rotation of the fetal head (Desbrière et al., 2013; Guittier et al., 2016; Le Ray et al., 2016). In view of the lack of convincing data, all studies recommend that the woman be offered the freedom to choose her position.

Many other practices are used during labor to help women manage their pain and to promote the progress of labor; these include epidural analgesia, nitrous oxide, and immersion in water (Anim-Somuah et al., 2011; Cluett and Burns, 2009; Jones et al., 2012; Lawrence et al. 2013). Nonetheless, some of them can have adverse side effects (such as nausea or vomiting with nitrous oxide) or even affect maternal outcome (e.g., there is an increased risk of assisted vaginal birth with epidural analgesia) (Anim-Somuah et al., 2011; Jones et al., 2012).

Our research hypothesis is that the practices of French midwives differ in some ways from those of their colleagues in other developed countries. Our overall goal is to develop data 
about practices in France that will provide an evidence base to study their relations with outcomes, as well as to help to improve initial and continuing midwifery education.

Accordingly, the principal objective of our study was to describe the practices reported by French midwives during labor (first stage and passive phase of the second stage). Our secondary objective was to assess whether these practices differ according to the midwives' practice experience or the level of the maternity ward where they work.

\section{Methods}

Design

We conducted a cross-sectional study via an internet survey of French midwives, both hospital-based and in private practice.

\section{Setting}

This open survey took place in France. Participants completed it on a website from June 15 through December 1, 2014. The midwives participating in this study were informed on the survey home page of the time required to complete the survey, their right to withdraw from the study (via a personal number obtained at the end of the study), and the study's objectives. No identifying information was collected.

\section{Participants and Recruitment process}

In our convenience sample, only midwives who attended at least one delivery in 2013 and who performed deliveries in equipped facilities legally required for providing deliveries (i.e., not home deliveries) were eligible. Midwives were recruited for the survey through the e-mail lists and websites of the national council of midwives and the national college of French midwives $(n=21,700)$. A single reminder e-mail was sent. The relevant ethics committee 
approved this study on March 31, 2014 (CECIC Rhône-Alpes-Auvergne, Grenoble, IRB 00005921).

\section{Variables}

The questionnaire covered the different practices known to be used in France at least occasionally, during all three stages of delivery, as well as some variables concerning the midwives (age, years of experience, etc.).

\section{Development and pretesting of the questionnaire}

The survey comprised 46 closed questions, 21 of which are used in this study (Supplementary File 1: the questionnaire). The midwives' characteristics (age, time in practice, place of practice, etc.) were defined from the answers to the first 11 survey questions. Eight questions were specific to the positions used during the first stage and the passive second stage. The first stage of labor was defined as the period from the diagnosis of labor onset through full dilation. The passive second stage of labor was defined by the period from the diagnosis of full dilatation until but not including the phase of expulsion. Vertical positions were defined as those "in which a line connecting the centers of the woman's third and fifth lumbar vertebrae is more nearly vertical than horizontal" and in which the third lumbar vertebra is higher than the fifth, while a horizontal (neutral) position is one in which the line is more nearly horizontal than vertical (Atwood, 1976). The vertical positions were differentiated according to their points of support (feet, buttocks, or knees). We limited the horizontal positions to three categories of positions: supine, lateral, and prone.

It was pilot tested by 10 midwives practicing in maternity wards of different levels (I, II, and III), different sizes ( $<500, \geq 500-\leq 1500$, and $>1500$ deliveries/year), and different statuses (public or private). Level I units have no neonatology department, while level II units have a department of neonatology in the same building as or in immediate proximity to the delivery 
suite, and level III units have, in addition to a neonatology unit, a neonatal intensive care in the same building as or in immediate proximity to the delivery room.

The online version was tested on different brands of computers and different versions of browser software.

\section{Survey administration and data sources}

The website was exclusively devoted to the survey, and the midwives had direct access to its information page. No incentives were offered for participation in this voluntary survey. Once the midwife agreed to complete the questionnaire, the first question was whether she had attended a delivery in 2013 (the inclusion criterion). If the response was negative, the survey ended.

The questions were organized following the chronology of labor and delivery and therefore did not randomize item order. We used some adaptive questions to streamline the questionnaire when possible. The items about positions during the first stage and the passive second stage were distributed over 4 screens, to differentiate clearly between women with and without epidural analgesia. All items were mandatory and the participant could not move to the next screen until the previous one was completed. The participants could however change their answers throughout the survey via the table of contents to the left of the questionnaire. Because many midwives responded from their workplace, and therefore several midwives used the same computer, software controls to prevent multiple entries from the same individuals could not be used. 
Study size

The study size was not pre-defined. We have no information about the number of midwives nationwide attending deliveries and were therefore unable to estimate power $a$ priori.

Recruitment took place over the study period (June 15 through December 1, 2014).

\section{Analysis}

Only completed questionnaires were analyzed; there was no time limit for their completion. Our principal outcome was the prevalence of the practices midwives reported. The responses are reported as percentages of all respondents. They were subsequently compared according to maternity unit level and according to the midwives' experience (years of practice) ( $\leq 5 \mathrm{vs}$. 6-15 vs. > 15). The Chi2 test (or Fisher's exact test, as appropriate) was used to compare the qualitative variables. Student's T test was used to analyze the quantitative variables. The threshold of significance was set at $p<0.05$. The statistical analyses were performed with SAS software (version 9.4, SAS Institute, Inc, Cary, NC, USA, 2002-2012).

\section{Findings}

Overall, 1550 midwives responded to the questionnaire, but 54 were ineligible for the study (27 midwives in private practice without access to an equipped facility and 27 midwives who qualified only in 2014). These 1496 midwives practiced in 377 maternity units. The participation rate in this study was $30.5 \%$, with the denominator calculated from the annual national statistics for French healthcare facilities (SAE). Table 1 summarizes the respondents' characteristics. They had been in practice for a mean of 9.7 years $\pm 8.1: 38.9 \%$ for 5 years or less, $40.7 \%$ for 6 to 15 years, and $20.4 \%$ for more than 15 years $(p=0.04)$. The largest percentage of respondents worked at level II maternity wards (44.5\% vs. $31 \%$ level III and $24.5 \%$ level I, $p=0.04)$. 


\section{First stage of labor}

\section{First stage of labor without epidural analgesia}

The midwives reported that they most often proposed that women use a birthing ball $(98.1 \%)$, walk around (97.4\%), or shower (76.2\%) during this stage (Table 2). These suggestions differed according to the level of their maternity ward. Midwives from level II (75.7\%) and level III $(73.5 \%)$ facilities reported offering epidural analgesia more often than by those at level I units (57.7\%) $(p<0.0001)$. Midwives in level I units proposed walking $(99.7 \%)$ more frequently than those in level II $(96.7 \%)$ or level III $(96.6 \%)$ units $(p=0.006)$ (Table 2$)$. Looking at the practices that differed by years of practice, we see that nearly half $(49.1 \%)$ the midwives with 5 years or less of clinical experience offered women nitrous oxide, but not quite a third of those $(29.8 \%)$ with more than 15 years of experience $(p<0.0001)$ (Table 2). Most midwives proposed a vertical sitting position (97.9\%) or a lateral position $(91.8 \%)$ (Table 3). Asked to choose their preferred position, the largest number chose sitting $(41.1 \%)$. Standing positions were proposed most often by midwives at level I units $(p=0.0005)$ (Table 3). Suggested positions did not differ according to midwives' experience.

First stage of labor with epidural analgesia

The midwives mainly proposed varying different horizontal positions (91.6\%) (Table 2). Supported standing was recommended more often by midwives in level I facilities than those elsewhere ( $p=0.001)$ (Table 2). The only suggested practice that differed according to midwives' experience was walking preferred most by midwives with $>15$ years of experience.

Midwives recommended nearly all of the lateral (98.9\%) and sitting positions (90.3\%) (Table 3) and reported they preferred the lateral position (68.1\%). Recommended positions did not 
differ according to maternity unit level, except for the standing position, most frequent among midwives working in level 1 units (Table 3). Midwives with $\leq 5$ years of practice suggested kneeling (72.3\%) and sitting (92.8\%) positions more often than the other midwives (Table 3).

Globally, during the first stage of labor, $85.8 \%$ of the midwives felt comfortable with all the positions, with those in level I facilities at ease most often $(90.4 \%$ vs. $84.8 \%$ in level II, and level $83.6 \%$ in level III, $p=0.01$ ), as well as those with 6 to 15 years of experience $(90.0 \%$ vs. $\leq 5$ years $81.1 \%,>15$ years $86.6 \%, p<0.0001)$.

\section{Passive second stage of labor}

Passive second stage of labor without epidural analgesia

During this phase, midwives mainly proposed various horizontal positions (83.9\%) or using a birthing ball (70.1\%) (Table 4). All the practices during this phase differed according to maternity unit level, with midwives in level III facilities recommending epidural analgesia most often ( $p=0.001)$ (Table 4). Inversely, midwives in level I units recommended immersion in water more often than those working in other levels $(p<0.0001)$ (Table 4). Practices also differed according to experience: midwives $\leq 5$ years of practice suggested nitrous oxide most often $(p<0.0001)$.

A lateral position was suggested most often, by $94.3 \%$ of midwives, followed by the kneeling vertical position (70.5\%) (Table 5). The midwives reported that they preferred the lateral position (45.2\%). Midwives in level I facilities proposed kneeling more often than the others $(p=0.004)$ (Table 5). The midwives with 6 to 15 years of experience suggested the hand-andknees ("all fours") position more often than the others $(p=0.02)$ (Table 5). 
Nearly all the midwives proposed changing between different horizontal positions $(95.5 \%)$ and more than a third use of the birthing ball (38.5\%) (Table 4). Midwives in level I units suggested the use of supported positions more often than those in more highly equipped facilities $(p=0.03)$ (Table 4$)$. The birthing ball was proposed by the younger midwives (in practice $\leq 5$ years) more often than by more experienced midwives $(p<0.0001)$ (Table 4$)$.

The midwives recommended many different positions, but the lateral position was their most common suggestion (97.3\%) (Table 5), and their preferred position (54.3\%). During this phase, suggestions did not differ according to maternity unit level, except that level II midwives proposed a lateral position more often than the others $(p=0.02)$. Practices concerning positions (kneeling, sitting, and supine), however, differed according to the midwives' experience (Table 5).

Globally, during the passive second stage of labor, $79.9 \%$ of the midwives felt comfortable with all positions; those in level I facilities ( $86.1 \%$ vs. $78.4 \%$ in level II and level $77.2 \%$ in level III, $p=0.02$ ) were most often at ease, as were those with 6 to 15 years of experience (85.4\% vs. $\leq 5$ years $73.9 \%,>15$ years $80.3 \%, p<0.0001)$.

\section{Discussion}

\section{Key results}

During the first stage of labor, midwives reported suggesting that women without epidural analgesia use a birthing ball (98.1\%) and walk around (97.4\%). For women with epidural analgesia, most suggested motion in horizontal positions. Epidural analgesia was proposed more often by midwives from level II (75.7\%) and level III (73.5\%) maternity wards than by those at level 1 units $(57.7 \%)(p<0.0001)$. The midwives preferred a lateral position during the first stage for women with epidural analgesia and during the second stage for all women. 


\section{Strengths and limitations}

Our low participation rate $(30.5 \%)$ (Eysenbach, 2004) is nonetheless an underestimate because the exact number of midwives participating in deliveries in each maternity ward in France is unavailable. We used the national database of healthcare facility statistics (SAE), which reports the number of midwives practicing in maternity units, regardless of the actual work they perform. Some midwives, however, no longer work in the delivery room (e.g., they may do prenatal and postnatal care, or administration), which artificially diminishes our participation rate. Moreover, it is known that participation rates are lower with online internet surveys than with paper surveys (Yetter and Capaccioli 2010). Our participation rate is nonetheless good for a survey of practices among the general population of midwives, since response rates in other general population-based studies have been less than $15 \%$ (Arrish et al., 2016; George et al., 2016; RCM, 2010). Some authors have obtained better response rates by limiting their study to a population sample (random drawing of some midwives who are members of an association or professional society) (Jones et al., 2011; Bick et al., 2012). We could not define a target sample to determine a representative sample of the population of French midwives involved in the delivery of babies because there is no national register of all French midwives that includes their professional characteristics. Moreover, French midwives are not required to join the French National College of Midwives (CNSF). Another weakness of our study is its reliance on midwives' self-report: professionals do not always do what they say they do!

In 2013, France had 519 maternity units (DRESS); accordingly, respondents reported practices in $72.7 \%$ of French public and private maternity units. Our population nonetheless appears younger than the national mean of midwives in 2014 (33.4 years vs. 40.2 years, DRESS) and worked more often predominantly in hospitals (92.9\% vs. 68.8\% in France 2014, DRESS). These results are consistent with the target population since the midwives 
participating in deliveries in France work mainly in hospitals and are younger than 40 years (Charrier, 2011). These distributions differ somewhat according to maternity unit level, status (private or public), and volume of delivery, but the differences correspond to the distribution of status and volume of French maternity units (Blondel and Kermarrec, 2011). In recent decades in France, small hospitals have been closing, and deliveries have become concentrated in large public maternity units.

\section{Interpretation}

Globally, the practices of French midwives were probably influenced by the fact that most deliveries occur in hospital settings and are accordingly over-medicalized. They thus offered epidural analgesia more often than alternatives, such as water immersion in a large tub or a shower during the first and second stages. Non-hospital births are quite rare in France, accounting for $0.9 \%$ of deliveries in 2013 (INSEE, 2014). Until 2015, maternity units in clinics and hospitals were the facilities most often available for deliveries in France because no other places of birth were clearly described in the French care pathway. Increasingly, midwives in private practice outside hospitals are working in partnership with a hospital maternity ward to provide their clients with complete care throughout pregnancy and continuous support during delivery (Nohuz et al., 2015). Our survey included 107 midwives with private or mixed practices. In 2016, the French government authorized the experimental opening of 9 birth centers (freestanding midwifery units) (CNOSF, 2015). These facilities, more widely developed in other countries, such as the United Kingdom, should help to reduce obstetric interventions for women with low-risk pregnancies, including use of epidural analgesia (Hollowell et al., 2015).

France has one of the highest rates of epidural analgesia for women with vaginal deliveries: $77 \%$ of women use it, and only $52 \%$ of those who want to give birth without it succeed in 
doing so (Kpéa et al., 2015). Moreover, only $8 \%$ of French maternity units offer "walking" epidurals, and without them, only a limited choice of positions is available for women who want strong pain relief (Blondel and Kermarrec, 2011).

During the first and second stages of labor, French midwives are more likely to offer horizontal positions, to the detriment of the upright positions described by Atwood (1976); the only exception is a seated position during the first stage only, and only for women without an epidural. Midwives most often propose the lateral position during the first stage with epidural analgesia and during the passive phase of the second stage, both with and without epidural analgesia.

Midwives in level I or II units proposed more practices and positions for women without epidural analgesia than did midwives in level III maternity wards. These results are consistent with those of 3 studies (Freeman et al., 2006; Priddis et al., 2012; Davis and Homer, 2016) that found maternal position to be influenced by other factors, including delivery room equipment, the midwife's practices and experience, and place of work. Their experience also appears to affect their practices, since those in practice for the fewest years offered the most alternatives to an epidural analgesic as well as a wider range of positions.

There are numerous international guidelines about normal delivery published, among others, by the learned societies of English and US midwives, and by the World Health Organization (WHO). No French guidelines for midwifery care during normal delivery currently exist, however, except for the recently issued recommendations concerning oxytocin augmentation (Dupont et al., 2017). In France, pregnant women are offered a free childbirth and parenting preparation course, in 7 sessions; delivery is one of the topics discussed. Midwives and other professionals can then explain different practices and positions for delivery and help women to choose appropriate positions for labor, according to de Jonge et al. (2008). 
In our study, the midwives most often proposed horizontal positions, while a UK survey of midwives found vertical positions used in $63 \%$ of births (RCM, 2010). The study by Freeman et al. (2006), however, reports practices similar to those of French midwives. The New Zealand midwives in that study reported, in chronological order through labor, that their patients walked first, then moved to a lateral position, followed by hands and knees, and finished by giving birth in a semi-reclined position. Nonetheless, the first choice for analgesic treatment in the study by Freeman et al. (2006) was nitrous oxide (55\%), and then epidural analgesia (29\%), while more midwives in our population recommended epidural $(70.6 \%)$ than nitrous oxide (43.5\%). Our results mirror those of a survey of French healthcare-system users, conducted by CIANE (Collectif Inter associatif Autour de la Naissance), a French group representing women having babies (i.e., using obstetrics and midwifery services). Among 5460 French women who gave birth in $2012,14 \%$ to $75 \%$ reported that they had not been able to use the positions they wanted during their delivery (CIANE, 2012). They thus concluded that "granting true freedom of movement and position to women appears to be a measure likely to improve the conditions of their delivery quite substantially." Nonetheless, a clear selection bias limits the results of their study.

In conclusion, the practices of French midwives include widespread recourse to epidural analgesia, the analgesic technique they suggest first. Nonetheless, they also use alternatives quite widely (e.g., immersion in water, shower, and nitrous oxide). French midwives propose multiple positions to parturients, but these suggestions vary according to the midwife's workplace and her experience. French practices do not appear to be totally identical to those of midwives in other countries, and an international survey on the subject would be interesting.

It would be useful to describe other practices of French midwives related to delivery, but also to identify in the French sentinel network databank AUDIPOG (this association involves 
public and private maternity units from every region in France that have volunteered to contribute individual data on mothers and infants, http://www.audipog.net) or through intermittent French surveys the real positions used during delivery, which would make it possible to identify the gap between what professionals say they do and what they actually do. The results of this study may also make it possible to improve the initial and continuing education of French midwives.

Funding: This work was supported by the Fondation de France [Midwifery Grant Mustela, 2013]; French Ministry of Health [PHRC-2005-05.09].

\section{References}

Anim-Somuah, M., Smyth, R.M., Jones, L., 2011. Epidural versus non-epidural or no analgesia in labour, in: Cochrane Database of Systematic Reviews. John Wiley \& Sons, Ltd. doi:10.1002/14651858.CD000331.pub3

Arrish, J., Yeatman, H., Williamson, M., 2016. Australian midwives and provision of nutrition education during pregnancy: A cross sectional survey of nutrition knowledge, attitudes, and confidence. Women and Birth. doi:10.1016/j.wombi.2016.03.001

Atwood, R.J., 1976. Parturitional posture and related birth behavior. Acta Obstetricia et Gynecologica Scandinavica.

Bick, D.E., Ismail, K.M., Macdonald, S., Thomas, P., Tohill, S., Kettle, C., 2012. How good are we at implementing evidence to support the management of birth related perineal trauma? A UK wide survey of midwifery practice. BMC Pregnancy and Childbirth. doi:10.1186/1471$2393-12-57$ 
Cluett, E.R., Burns, E., 2009. Immersion in water in labour and birth, in: Cochrane Database of Systematic Reviews. John Wiley \& Sons, Ltd. doi:10.1002/14651858.CD000111.pub3

Davis, D.L., Homer, C.S.E., 2016. Birthplace as the midwife's work place: How does place of birth impact on midwives? Women and Birth 29, 407-415. doi:10.1016/j.wombi.2016.02.004

De Jonge, A., Teunissen, D.A.M., Van Diem, M.T., Scheepers, P.L.H., Lagro-Janssen, A.L.M., 2008. Women's positions during the second stage of labour: views of primary care midwives. Journal of Advanced Nursing. doi:10.1111/j.1365-2648.2008.04703.x

Desbriere, R., Blanc, J., Le Dû, R., Renner, J.-P., Carcopino, X., Loundou, A., d'Ercole, C., 2013. Is maternal posturing during labor efficient in preventing persistent occiput posterior position? A randomized controlled trial. American Journal of Obstetrics and Gynecology. doi:10.1016/j.ajog.2012.10.882

Dupont, C., Carayol, M., Le Ray, C., Deneux-Tharaux, C., Riethmuller, D., 2017. Oxytocin administration during spontaneous labor: Guidelines for clinical practice. Guidelines short text. Journal of Gynecology Obstetrics and Human Reproduction.

doi:10.1016/j.jogoh.2017.04.010

Eysenbach, G., 2004. Improving the Quality of Web Surveys: The Checklist for Reporting Results of Internet E-Surveys (CHERRIES). Journal of Medical Internet Research. doi:10.2196/jmir.6.3.e34

Fitzpatrick, M., McQuillan, K., O’Herlihy, C., 2001. Influence of persistent occiput posterior position on delivery outcome. Obstetrics \& Gynecology.

Freeman, L.M., Adair, V., Timperley, H., West, S.H., 2006. The influence of the birthplace and models of care on midwifery practice for the management of women in labour. Women and Birth. doi:10.1016/j.wombi.2006.10.001 
George, A., Dahlen, H.G., Blinkhorn, A., Ajwani, S., Bhole, S., Ellis, S., Yeo, A., Elcombe, E., Sadozai, A., Johnson, M., 2016. Measuring oral health during pregnancy: sensitivity and specificity of a maternal oral screening (MOS) tool. BMC Pregnancy and Childbirth. doi:10.1186/s12884-016-1140-4

Guittier, M., Othenin-Girard, V., de Gasquet, B., Irion, O., Boulvain, M., 2016. Maternal positioning to correct occiput posterior fetal position during the first stage of labour: a randomised controlled trial. BJOG: An International Journal of Obstetrics \& Gynaecology. doi:10.1111/1471-0528.13855

Gupta, J.K., Nikodem, C., 2000. Maternal posture in labour. European. European Journal of Obstetrics \& Gynecology and Reproductive Biology.

Gupta, J.K., Hofmeyr, G.J., Shehmar, M., 2012. Position in the second stage of labour for women without epidural anaesthesia, in: The Cochrane Collaboration (Ed.), Cochrane Database of Systematic Reviews. John Wiley \& Sons, Ltd, Chichester, UK. doi:10.1002/14651858.CD002006.pub3

Hollowell, J., Rowe, R., Townend, J., Knight, M., Li, Y., Linsell, L., Redshaw, M., Brocklehurst, P., Macfarlane, A., Marlow, N., McCourt, C., Newburn, M., Sandall, J., Silverton, L., 2015. The Birthplace in England national prospective cohort study: further analyses to enhance policy and service delivery decision-making for planned place of birth. Health Services and Delivery Research. doi:10.3310/hsdr03360

Jones, C.J., Creedy, D.K., Gamble, J.A., 2011. Australian Midwives’ Knowledge of Antenatal and Postpartum Depression: A National Survey. Journal of Midwifery \& Women's Health. doi:10.1111/j.1542-2011.2011.00039.x 
Jones, L., Othman, M., Dowswell, T., Alfirevic, Z., Gates, S., Newburn, M., Jordan, S., Lavender, T., Neilson, J.P., 2012. Pain management for women in labour: an overview of systematic reviews, in: Cochrane Database of Systematic Reviews. John Wiley \& Sons, Ltd. doi:10.1002/14651858.CD009234.pub2

Kemp, E., Kingswood, C.J., Kibuka, M., Thornton, J.G., 2013. Position in the second stage of labour for women with epidural anaesthesia, in: The Cochrane Collaboration (Ed.), Cochrane Database of Systematic Reviews. John Wiley \& Sons, Ltd, Chichester, UK. doi:10.1002/14651858.CD008070.pub2

Kpéa, L., Bonnet, M.-P., Le Ray, C., Prunet, C., Ducloy-Bouthors, A.-S., Blondel, B., 2015. Initial Preference for Labor Without Neuraxial Analgesia and Actual Use: Results from a National Survey in France. Anesthesia \& Analgesia. doi:10.1213/ANE.0000000000000832

Lawrence, A., Lewis, L., Hofmeyr, G.J., Styles, C., 2013. Maternal positions and mobility during first stage labour, in: The Cochrane Collaboration (Ed.), Cochrane Database of Systematic Reviews. John Wiley \& Sons, Ltd, Chichester, UK. doi:10.1002/14651858.CD003934.pub3

Le Ray, C., Lepleux, F., De La Calle, A., Guerin, J., Sellam, N., Dreyfus, M., Chantry, A., 2016. Lateral Asymmetric Decubitus position for the rotation of occipito-posterior positions: multicenter randomized controlled trial EVADELA. American Journal of Obstetrics and Gynecology. doi:10.1016/j.ajog.2016.05.033

Lieberman, E., Davidson, K., Lee-Parritz, A., Shearer, E., 2005. Changes in Fetal Position During Labor and Their Association With Epidural Analgesia: Obstetrics \& Gynecology.doi:10.1097/01.AOG.0000158861.43593.49 
Nohuz, E., Tarraga, E., Albaut, M., De Simone, L., Gerbaud, L., 2015. « Accouchement sur un plateau » : l'épopée d'une maternité dans l'octroi de son plateau technique aux sagesfemmes libérales. Gynécologie Obstétrique \& Fertilité. doi:10.1016/j.gyobfe.2015.03.018

Priddis, H., Dahlen, H., Schmied, V., 2012. What are the facilitators, inhibitors, and implications of birth positioning? A review of the literature. Women and Birth. doi:10.1016/j.wombi.2011.05.001

Royal College of Midwives (RCM), 2010 .The Royal College of Midwives' Survey of positions used in labour and birth. London : RCM.

Yetter, G., Capaccioli, K., 2010. Differences in responses to Web and paper surveys among school professionals. Behavior Research Methods. doi:10.3758/BRM.42.1.266

\section{Web references}

Association des Utilisateurs de Dossiers Informatisés en Pédiatrie, Obstétrique et Gynécologie (Audipog), http://www.audipog.net/interro-choix.php?langue=en

Bellamy V., Beaumel C., 2016. Bilan démographique 2015 : le nombre de décès au plus haut depuis l'après-guerre. Insee Première. https://www.insee.fr/fr/statistiques/1908103

Blondel B., Kermarrec M., 2011. Les naissances en 2010 et leur évolution depuis 2003. In Enquête nationale périnatale 2010. Institut national de la santé et de la recherche médicale, Ministère du travail de l'emploi et de la Santé, Paris. http://socialsante.gouv.fr/IMG/pdf/Les_naissances_en_2010_et_leur_evolution_depuis_2003.pdf Charrier P., 2011. Les sages-femmes en France : Rapport de recherche. https://halshs.archives-ouvertes.fr/halshs-00584595/document 
Collectif interassociatif autour de la naissance (French group representing women having babies) (CIANE), 2012. Respect des souhaits et vécu de l'accouchement. http://ciane.net/wordpress/wp-content/uploads/2012/09/EtudeSouhaits.pdf

Conseil national de l'ordre des sages-femmes (CNOSF), 2015. Maisons de naissance : neuf structures ouvriront bintôt leurs portes. http://www.ordre-sages-femmes.fr/actualites/maisonsde-naissance-neuf-structures-ouvriront-bientot-leurs-portes/

Direction de la Recherche, des études et de l'évaluation et des statistiques (Bureau of research, studies, evaluation and statistics) (DRESS), http://www.data.drees.sante.gouv.fr/

Institut national de la statistique et des études économiques (National institute of statistics and economic studies) (INSEE), 2014. Les naissances en 2013 - Tableaux France. https://www.insee.fr/fr/statistiques/2046467?sommaire=2106233

Statistique Annuelle des Etablissements de Santé (Annual Health Facility Statistics) (SAE), https://www.sae-diffusion.sante.gouv.fr/ 
Table 1 - Characteristics of responding midwives, globally, by maternity unit levels, and by midwives' experience

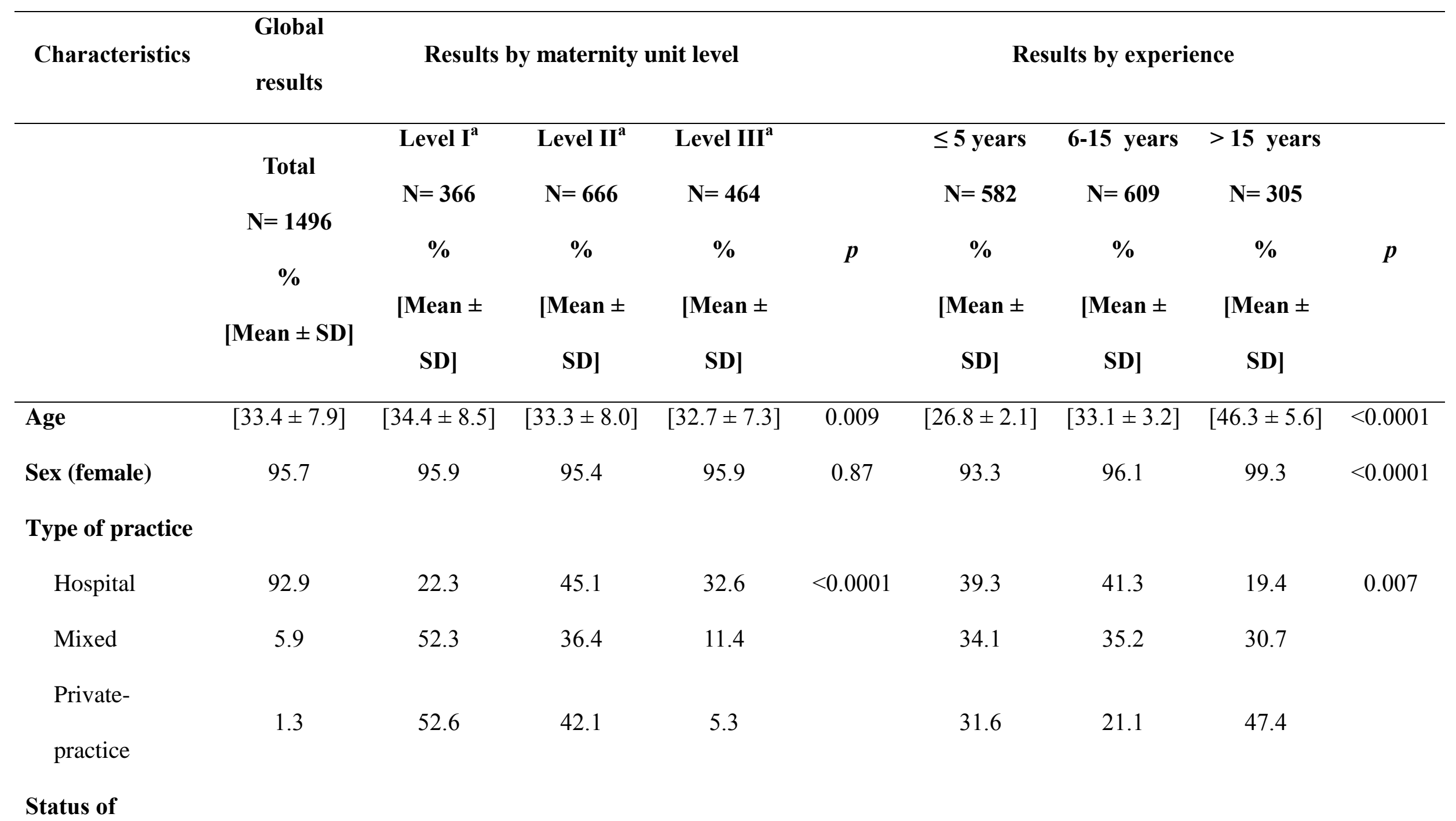


maternity

\begin{tabular}{|c|c|c|c|c|c|c|c|c|c|}
\hline Public & 84.2 & 19.0 & 44.2 & 36.9 & $<0.0001$ & 38.3 & 41.9 & 19.9 & 0.11 \\
\hline Private & 12.4 & 51.9 & 48.1 & 0 & & 43.2 & 31.9 & 24.9 & \\
\hline Other & 3.5 & 59.6 & 40.4 & 0 & & 38.5 & 44.2 & 17.3 & \\
\hline \multicolumn{10}{|l|}{ Deliveries/year } \\
\hline$<500$ & 35.6 & 32.8 & 41.3 & 25.9 & $<0.0001$ & 37.5 & 40.7 & 21.8 & $<0.0001$ \\
\hline$\geq 500-\leq 1500$ & 23.6 & 47.3 & 51.6 & 1.1 & & 35.4 & 40.5 & 24.1 & \\
\hline$>1500$ & 40.8 & 3.9 & 43.3 & 52.8 & & 42.1 & 40.8 & 17.1 & \\
\hline
\end{tabular}

${ }^{\mathrm{a}}$ Level I = maternity ward without a neonatology department; Level II = maternity ward with a neonatology department; Level III = maternity unit with a neonatology department and a neonatal intensive care unit (NICU). 
Table 2 - Practices proposed by midwives during the first stage, globally and by maternity unit level and by midwives' experience.

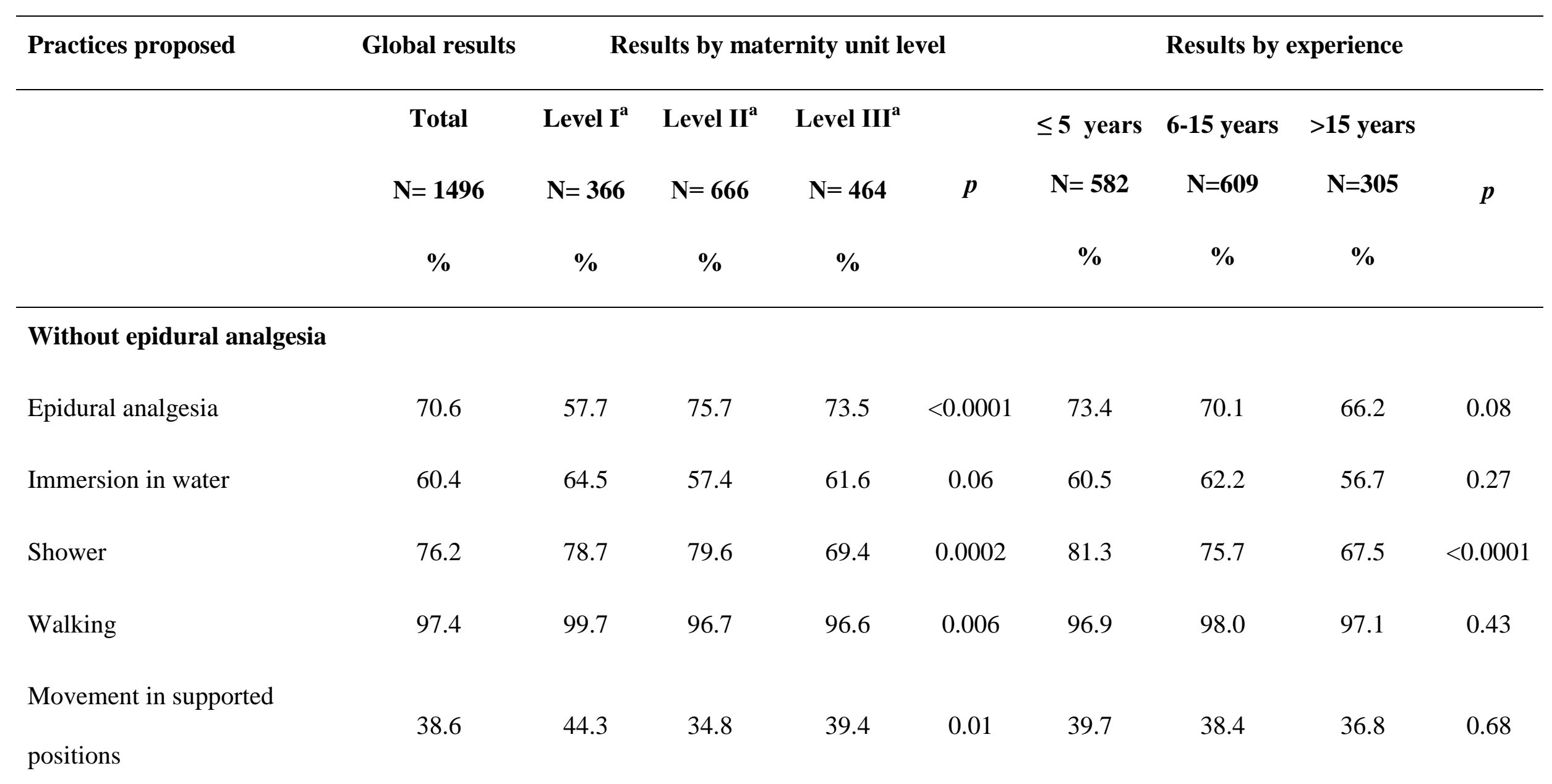




\begin{tabular}{|c|c|c|c|c|c|c|c|c|c|}
\hline Nitrous oxide & 43.5 & 42.1 & 45.2 & 42.2 & 0.5 & 49.1 & 45.0 & 29.8 & $<0.0001$ \\
\hline Birthing ball & 98.1 & 98.6 & 98.8 & 96.8 & 0.03 & 98.1 & 98.2 & 98.0 & 0.98 \\
\hline $\begin{array}{l}\text { Movement in horizontal } \\
\text { positions }\end{array}$ & 63.9 & 66.1 & 64.3 & 61.6 & 0.40 & 63.2 & 64.0 & 64.9 & 0.88 \\
\hline With epidural analgesia & & & & & & & & & \\
\hline Walking & 21.7 & 22.7 & 24.0 & 17.5 & 0.03 & 19.9 & 19.9 & 28.5 & 0.005 \\
\hline $\begin{array}{l}\text { Movement in supported } \\
\text { positions }\end{array}$ & 15.6 & 21.3 & 12.6 & 15.3 & 0.001 & 14.6 & 16.1 & 16.4 & 0.71 \\
\hline Birthing ball & 56.8 & 56.6 & 59.3 & 53.5 & 0.14 & 58.6 & 56.2 & 54.8 & 0.5 \\
\hline $\begin{array}{l}\text { Movement in horizontal } \\
\text { positions }\end{array}$ & 91.6 & 91.3 & 92.3 & 91.0 & 0.67 & 92.1 & 92.6 & 88.9 & 0.14 \\
\hline
\end{tabular}

${ }^{\mathrm{a}}$ Level I = maternity ward without a neonatology department; Level II = maternity ward with a neonatology department; Level III = maternity unit with a neonatology department and a NICU. 
Table 3 - Positions proposed by midwives during the first stage, globally and by maternity unit level and by midwives' experience.

\begin{tabular}{|c|c|c|c|c|c|c|c|c|c|}
\hline \multirow[t]{2}{*}{ Maternal positions } & \multirow{2}{*}{$\begin{array}{c}\text { Global results } \\
\text { Total }\end{array}$} & \multicolumn{4}{|c|}{ Results by maternity unit level } & \multicolumn{4}{|c|}{ Results by experience } \\
\hline & & Level $\mathbf{I}^{\mathbf{a}}$ & Level II ${ }^{\mathbf{a}}$ & Level III ${ }^{\mathrm{a}}$ & & $\leq 5$ years & 6-15 years & $>15$ years & \\
\hline & $N=1496$ & $N=366$ & $N=666$ & $\mathrm{~N}=464$ & $p$ & $\mathrm{~N}=\mathbf{5 8 2}$ & $N=609$ & $\mathbf{N}=\mathbf{3 0 5}$ & $p$ \\
\hline & $\%$ & $\%$ & $\%$ & $\%$ & & $\%$ & $\%$ & $\%$ & \\
\hline \multicolumn{10}{|l|}{ Without epidural analgesia } \\
\hline Standing position & 32.3 & 40.2 & 31.1 & 27.8 & 0.0005 & 29.6 & 33.8 & 34.4 & 0.19 \\
\hline Kneeling position & 69.6 & 70.8 & 69.7 & 68.5 & 0.78 & 69.6 & 70.6 & 67.5 & 0.64 \\
\hline Lateral position & 91.8 & 94.0 & 91.7 & 90.1 & 0.13 & 90.6 & 92.6 & 92.5 & 0.38 \\
\hline Prone position & 61.0 & 65.6 & 60.5 & 58.2 & 0.09 & 62.4 & 57.6 & 65.3 & 0.06 \\
\hline
\end{tabular}

With epidural analgesia 


\begin{tabular}{|c|c|c|c|c|c|c|c|c|c|}
\hline Standing position & 4.9 & 7.7 & 4.1 & 3.9 & 0.02 & 3.3 & 5.8 & 6.3 & 0.06 \\
\hline Kneeling position & 68.7 & 70.8 & 67.9 & 68.1 & 0.6 & 72.3 & 70.1 & 58.7 & 0.0001 \\
\hline Sitting position & 90.3 & 90.7 & 90.8 & 89.2 & 0.63 & 92.8 & 89.7 & 86.9 & 0.01 \\
\hline Supine position & 76.1 & 74.3 & 77.9 & 74.8 & 0.32 & 79.4 & 77.3 & 67.2 & 0.0002 \\
\hline Lateral position & 98.9 & 99.2 & 99.3 & 98.1 & 0.14 & 99.3 & 98.7 & 98.4 & 0.39 \\
\hline Prone position & 51.7 & 54.4 & 50.8 & 50.9 & 0.49 & 56.0 & 47.8 & 51.2 & 0.02 \\
\hline
\end{tabular}

${ }^{\mathrm{a}}$ Level I = maternity ward without a neonatology department; Level II = maternity ward with a neonatology department; Level III = maternity unit with a neonatology department and a NICU. 
Table 4 - Practices proposed by midwives during the passive second stage, globally and by maternity unit level and by midwives' experience.

\begin{tabular}{|c|c|c|c|c|c|c|c|c|c|}
\hline \multirow[t]{2}{*}{ Practices proposed } & $\begin{array}{l}\text { Global } \\
\text { results }\end{array}$ & \multicolumn{4}{|c|}{ Results by maternity unit level } & \multicolumn{4}{|c|}{ Results by experience } \\
\hline & Total & Level I ${ }^{\mathrm{a}}$ & Level II $^{\mathrm{a}}$ & Level III $^{\mathrm{a}}$ & & $\leq 5$ years & 6-15 years & $>15$ years & \\
\hline & $N=1496$ & $\mathrm{~N}=366$ & $N=666$ & $N=464$ & $p$ & $\mathrm{~N}=582$ & $N=609$ & $\mathrm{~N}=305$ & $p$ \\
\hline \multicolumn{10}{|c|}{ Without epidural analgesia } \\
\hline Epidural analgesia & 43.7 & 35.5 & 46.0 & 46.8 & 0.001 & 43.3 & 43.0 & 45.6 & 0.75 \\
\hline Walking & 54.4 & 59.3 & 55.3 & 49.4 & 0.01 & 56.2 & 54.7 & 50.5 & 0.27 \\
\hline \multicolumn{10}{|l|}{ Movement in supported } \\
\hline positions & 42.3 & 51.9 & 38.1 & 40.7 & $<0.0001$ & 45.2 & 43.4 & 34.8 & 0.009 \\
\hline
\end{tabular}




\begin{tabular}{|c|c|c|c|c|c|c|c|c|c|}
\hline Nitrous oxide & 53.0 & 52.7 & 54.5 & 51.2 & 0.52 & 58.6 & 55.0 & 38.4 & $<0.0001$ \\
\hline Birthing ball & 70.1 & 73.2 & 71.6 & 65.5 & 0.03 & 75.3 & 67.8 & 64.9 & 0.002 \\
\hline \multicolumn{10}{|c|}{ Movement in horizontal } \\
\hline & 83.9 & 84.4 & 83.3 & 84.3 & 0.87 & 83.5 & 84.7 & 83.0 & 0.74 \\
\hline \multicolumn{10}{|l|}{ positions } \\
\hline \multicolumn{10}{|c|}{ With epidural analgesia } \\
\hline Walking & 5.4 & 6.6 & 6.3 & 3.2 & 0.04 & 4.6 & 5.6 & 6.7 & 0.47 \\
\hline \multicolumn{10}{|c|}{ Movement in supported } \\
\hline \multicolumn{10}{|l|}{ positions } \\
\hline Birthing ball & 38.5 & 35.5 & 41.0 & 37.3 & 0.18 & 46.2 & 34.7 & 31.5 & $<0.0001$ \\
\hline \multicolumn{10}{|c|}{ Movement in horizontal } \\
\hline positions & 95.5 & 94.5 & 95.4 & 96.3 & 0.46 & 94.9 & 96.6 & 94.4 & 0.23 \\
\hline
\end{tabular}

${ }^{\mathrm{a}}$ Level I = maternity ward without a neonatology department; Level II = maternity ward with a neonatology department; Level III = maternity unit with a neonatology department and a NICU. 
Table 5 - Positions proposed by midwives during the passive second stage, globally and by maternity unit level and by midwives' experience

\begin{tabular}{|c|c|c|c|c|c|c|c|c|c|}
\hline \multirow[t]{2}{*}{ Maternal positions } & \multirow{2}{*}{$\begin{array}{c}\text { Global results } \\
\text { Total }\end{array}$} & \multicolumn{4}{|c|}{ Results by maternity unit level } & \multicolumn{4}{|c|}{ Results by experience } \\
\hline & & Level I ${ }^{\mathbf{a}}$ & Level II ${ }^{\mathrm{a}}$ & Level III $^{\mathbf{a}}$ & & $\leq 5$ years & 6-15 years & $>15$ years & \\
\hline & $N=1496$ & $\mathrm{~N}=366$ & $N=666$ & $N=464$ & $p$ & $\mathrm{~N}=\mathbf{5 8 2}$ & $N=609$ & $\mathbf{N}=305$ & $p$ \\
\hline & $\%$ & $\%$ & $\%$ & $\%$ & & $\%$ & $\%$ & $\%$ & \\
\hline \multicolumn{10}{|l|}{ Without epidural analgesia } \\
\hline Standing position & 32.8 & 41.0 & 30.2 & 30.0 & 0.0006 & 32.3 & 36.0 & 27.2 & 0.03 \\
\hline Kneeling position & 70.5 & 76.0 & 71.0 & 65.5 & 0.004 & 69.9 & 73.9 & 64.9 & 0.02 \\
\hline Sitting position & 61.2 & 66.1 & 60.5 & 58.4 & 0.06 & 59.1 & 61.7 & 64.3 & 0.31 \\
\hline Supine position & 55.7 & 59.8 & 53.5 & 55.6 & 0.14 & 54.8 & 55.2 & 58.4 & 0.57 \\
\hline Lateral position & 94.3 & 94.5 & 94.9 & 93.3 & 0.52 & 95.0 & 93.9 & 93.8 & 0.64 \\
\hline Prone position & 57.0 & 59.8 & 55.6 & 56.7 & 0.41 & 60.5 & 54.4 & 55.4 & 0.09 \\
\hline
\end{tabular}




\begin{tabular}{|c|c|c|c|c|c|c|c|c|c|}
\hline Standing position & 2.9 & 4.6 & 2.6 & 1.9 & 0.05 & 2.2 & 3.6 & 2.6 & 0.35 \\
\hline Supine position & 74.3 & 73.2 & 75.1 & 74.1 & 0.80 & 78.4 & 75.0 & 65.3 & 0.0001 \\
\hline Prone position & 56.2 & 57.4 & 54.8 & 57.3 & 0.62 & 59.3 & 53.5 & 55.7 & 0.13 \\
\hline
\end{tabular}

${ }^{\mathrm{a}}$ Level I = maternity ward without a neonatology department; Level II = maternity ward with a neonatology department; Level III = maternity unit with a neonatology department and a NICU. 